\title{
Nicotine Dependence/Addiction on Treatment
}

National Cancer Institute

\section{Source}

National Cancer Institute. Nicotine Dependence/Addiction on Treatment. NCI Thesaurus.

Code C15985.

Research Studies that assess the behavioral and/or pharmacological treatment of individuals for nicotine dependence/addiction. The specific focus of treatment interventions is the individual in clinical and physician-based settings. ( $\mathrm{NCI} / \mathrm{T} \mathrm{RIP}$ ) 